\title{
Herbimycin A, a pp60 c-src Tyrosine Kinase Inhibitor, Inhibits Osteoclastic Bone Resorption In Vitro and Hypercalcemia In Vivo
}

\author{
Toshiyuki Yoneda, Carolyn Lowe, Chang-Ho Lee, Gloria Gutierrez, Maria Niewolna, Paul J. Williams, Elzbieta Izbicka, \\ Yosimasa Uehara, * and Gregory R. Mundy \\ University of Texas Health Science Center at San Antonio, Department of Medicine, Division of Endocrinology and Metabolism, San \\ Antonio, Texas 78284; and *Department of Bioactive Molecules, National Institute of Health, Toyama, Shinjuku-Ku, Tokyo 162, Japan
}

\begin{abstract}
Since absence of expression of the c-src gene product in mice indicates that the pp60 ${ }^{\mathrm{c}-s r}$ tyrosine kinase is required and essential for osteoclastic bone resorption, we tested the effects of the antibiotic herbimycin $A$, which is an inhibitor of pp60 ${ }^{\mathrm{c}-s x c}$ on osteoclastic bone resorption in vitro and on hypercalcemia in vivo. We examined the effects of herbimycin $A$ on the formation of bone resorbing osteoclasts in mouse long-term marrow cultures, on isolated rodent osteoclasts and on bone resorption in organ cultures of fetal rat long bones stimulated by parathyroid hormone. We found that herbimycin $A$ in concentrations of 1-100 $\mathrm{ng} / \mathrm{ml}$ inhibited bone resorption in each of these systems. We determined the effects of herbimycin A $(100 \mathrm{ng} / \mathrm{ml})$ on src tyrosine kinase activity in mouse marrow cultures and found that it was decreased. Herbimycin A also decreased elevated blood calcium levels that were induced either by repeated subcutaneous injections of recombinant human interleukin-1 $\alpha$ or by a human tumor. There was no evidence for toxicity in any of these culture systems or in mice treated with herbimycin $A$. A different tyrosine kinase inhibitor that does not inhibit pp60 ${ }^{\text {c-src }}$ was used as a control and caused none of these effects. These data suggest that pp60 ${ }^{\text {c-snc }}$ tyrosine kinase inhibitors may be useful pharmacologic inhibitors of osteoclastic bone resorption and hypercalcemia. (J. Clin. Invest. 1993.91:27912795.) Key words: pp60 ${ }^{\text {c-src }} \cdot$ tyrosine kinase inhibitors $\bullet$ osteoclast $\bullet$ bone resorption $\cdot$ hypercalcemia
\end{abstract}

\section{Introduction}

Recent observations suggest that different tyrosine kinases (TKs) ${ }^{1}$ may be essential for normal osteoclastic bone resorption. Mice deficient in expression of the c-src protooncogene by introduction of the null mutation into the germ line by homolo-

Address correspondence and reprint requests to Dr. Toshiyuki Yoneda, Division of Endocrinology and Metabolism, Department of Medicine, The University of Texas Health Science Center at San Antonio, 7703 Floyd Curl Dr., San Antonio, TX 78284-7877.

Received for publication 18 November 1992 and in revised form 12 January 1993.

1. Abbreviations used in this paper: $\alpha \mathrm{PY}$, antiphosphotyrosine antibody; $\mathrm{Ca}^{2+}$, whole-blood ionized calcium; PTH, parathyroid hormone; rh-IL- $1 \alpha$, recombinant human IL- $1 \alpha$; TK, tyrosine kinase; TRAP $(+) M N C$, tartrate-resistant acid phosphatase-positive multinucleated cells; $1,25 \mathrm{D}_{3}, 1,25$-dihydroxyvitamin $\mathrm{D}_{3}$.

J. Clin. Invest.

(C) The American Society for Clinical Investigation, Inc.

$0021-9738 / 93 / 06 / 2791 / 05 \$ 2.00$

Volume 91, June 1993, 2791-2795 gous recombination develop osteopetrosis ( 1). These data indicate that the TK encoded by src is required for normal osteoclast function. Recently, an antibiotic herbimycin $A$ that inhibits a number of intracellular TKs, including the src TK, has been identified. This antibiotic has been shown to reverse temperature sensitive respiratory syncytial virus (RSV)-transformed rat cells (ts/NRK) morphology to normal, concomitant with a marked reduction in pp60 ${ }^{\text {src }}$ kinase activity. Herbimycin A irreversibly and directly inhibits pp $60^{\mathrm{v}-s r c} \mathrm{TK}$ but has no effects on serine/threonine kinase, protein kinase $A$, and protein kinase $C(2)$. To determine if herbimycin $A$ could be a useful inhibitor of osteoclastic bone resorption, we tested its effects on bone resorption stimulated by parathyroid hormone (PTH) in three different in vitro systems that examine different aspects of osteoclast function, namely osteoclast formation, as well as osteoclastic activation and resorption. We also found that herbimycin $\mathrm{A}$ inhibited hypercalcemia in mice that was induced either by repeated injections of recombinant human IL- $1 \alpha$ (rhIL- $1 \alpha)$ or by a human tumor. We examined another TK inhibitor, RG-13022 (3, 4), as a control. RG-13022 showed none of these effects.

\section{Methods}

Drugs

RG-13022 was kindly supplied by Dr. A. Zilberstein (Rhône-Poulenc Rorer Biotechnology, Collegeville, PA). Fig. 1 shows the structure of herbimycin A and RG-13022. Stock solutions of the drugs were made in 100\% DMSO and diluted with the culture medium before addition to cells. The culture medium containing the equivalent concentrations of DMSO served as vehicle controls.

\section{Fetal rat long bone assay}

This assay measures the release of previously incorporated ${ }^{45} \mathrm{Ca}$ from fetal rat long bones in organ culture, and has been described previously (5). Four bones were cultured per group, and bone resorbing activity was expressed as treated: control ratios of ${ }^{45} \mathrm{Ca}$ released from test and control bones. Statistical significance was assessed using the Student's $t$ test for unpaired samples.

\section{Murine marrow cell culture system}

We used a modification of the murine marrow culture technique described by Takahashi et al. (6). Marrow cells were collected from the femora and tibiae, washed twice with $\alpha \mathrm{MEM}$ (Hazleton Biologics Inc., Lenexa, KS) and resuspended in $\alpha$ MEM supplemented with $10 \%$ FCS (Hyclone Laboratories, Logan, UT) and without antibiotics at a final density of $4 \times 10^{6}$ cells $/ \mathrm{ml}$. $0.5 \mathrm{ml}$ of cell suspension per well was inoculated onto 24-well plates (Corning Inc., Corning, NY) and $10^{-8}$ M 1,25-dihydroxyvitamin $\mathrm{D}_{3}\left(1,25 \mathrm{D}_{3}\right)$ (Biomol Research Laboratories Inc., Plymouth Meeting, PA) in $10 \mu \mathrm{l}$ was added to each well. Cultures were maintained at $37^{\circ} \mathrm{C}$ in a humidified atmosphere of $5 \%$ $\mathrm{CO}_{2}$ in air. The cells were fed every $2 \mathrm{~d}$ with $0.3 \mathrm{ml}$ of fresh $\alpha \mathrm{MEM}$ with $10 \%$ FCS and $10^{-8} \mathrm{M} 1,25 \mathrm{D}_{3}$. After $6 \mathrm{~d}$, the cultures were washed in PBS, fixed in $60 \%$ acetone in citrate buffer pH 5.4 for $30 \mathrm{~s}$, air dried, and stained for tartrate-resistant acid phosphatase (TRAP) using a 
RG 13022<smiles>COc1ccc(/C=C(\C=N)c2cccnc2)cc1OC</smiles>

\section{Herbimycin A}

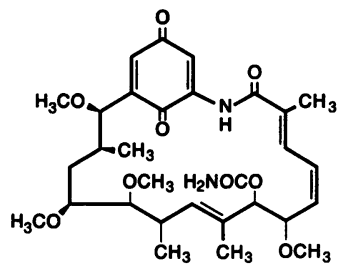

Figure 1. Chemical structure of RG-13022 and herbimycin A.

commercially available kit (Sigma Chemical Co., St. Louis, MO). Stained cultures were examined under light microscopy at a magnification of 40 TRAP-positive (red-staining) multinucleated (five or more nuclei) cells (TRAP $(+) \mathrm{MNC}$ ) were easily distinguishable from other cells present. All TRAP( +$)$ MNCs in each well were counted by manually scanning across the entire well in a systematic fashion.

\section{Assay for bone-resorbing activity of disaggregated rat osteoclasts}

Osteoclasts obtained for these experiments were prepared from the femora and tibiae of newborn rats according to techniques previously described $(7,8)$. The bones of each rat were curetted with a scalpel blade into $1 \mathrm{ml}$ of medium and vigorously agitated with a pipette. The supernatants were added to slices of sperm whale dentine. The cells were then incubated for $15 \mathrm{~min}$ at $37^{\circ} \mathrm{C}$. Dentine slices were then removed, washed, and placed in separate wells containing $100 \mu \mathrm{l}$ of $\alpha \mathrm{MEM}$ supplemented with $10 \%$ FCS. The wells were incubated in the absence or presence of bovine PTH (1-34; Peninsula Laboratories Inc., Belmont, $\mathrm{CA}$ ) for $24 \mathrm{~h}$ before quantification of cell numbers and assessment of bone resorption.

The disaggregated rat osteoclast pit assay was performed as described by Boyde et al. (9). Slices of sperm whale dentine $(0.25 \times 4 \times 6$ $\mathrm{mm}$ ) were prepared using a low speed diamond saw (Buehler Ltd., Lake Bluff, IL), followed by sonication ( $15 \mathrm{~min}$ ) in several changes of distilled water. Slices were smoothened between two glass plates and sterilized under ultraviolet light for $4 \mathrm{~d}$. Before all experiments, slices were incubated in $\alpha$ MEM supplemented with $5 \%$ FCS and $1 \%$ penicillin-streptomycin solution (Gibco Laboratories, Grand Island, NY) for $\geq 48 \mathrm{~h}$. Cultures were performed in humidified air $\left(10 \% \mathrm{CO}_{2}\right)$ at $37^{\circ} \mathrm{C}$ (one slice per well). A single experiment used 16-20 slices, with a minimum of three to four slices per treatment. Experiments were repeated at least three to four times. For examination of resorption lacunae, the slices are sonicated in $0.1 \mathrm{M} \mathrm{NaOH}$ and stained with $0.1 \%$ (wt/vol) toluidine blue. Lacunae were counted using light microscopy, and the plan area of matrix resorbed was quantitated using a computerassisted morphometric program on an image and process analysis system (Olympus Corp., Lake Success, NY). Data were analyzed by pattern analysis of variance $(8)$.

\section{Cell lysis}

Mouse bone marrow cells were cultured in the presence of $10^{-8} \mathrm{M}$ $1,25 \mathrm{D}_{3}$ for $6 \mathrm{~d}$ in six-well plates as described above. The cells were then treated with or without herbimycin A for $24 \mathrm{~h}$, followed by $50 \mathrm{ng} / \mathrm{ml}$ PTH, which is known to cause increased resorption pit formation by TRAP-positive MNC (6), for $30 \mathrm{~min}$. At the end of PTH incubation, cells were washed with ice-cold PBS twice, lysed at $4^{\circ} \mathrm{C}$ with $300 \mu \mathrm{l}$ solubilization buffer ( $10 \mathrm{mM}$ Tris, $50 \mathrm{mM} \mathrm{NaCl}, 30 \mathrm{mM}$ sodium pyrophosphate, $50 \mathrm{mM}$ sodium fluoride, $100 \mu \mathrm{M}$ sodium orthovandate, 2 $\mathrm{mM}$ iodoacetic acid, $2 \mathrm{mM} N$-ethylmaleimide, $1 \mathrm{mM}$ phenylmethylsulfnyl fluoride, $5 \mu \mathrm{M} \mathrm{ZnCl}$, and $1 \%$ Triton $\mathrm{X}-100, \mathrm{pH} 7.1$ ) (10), centrifuged at $13,000 \mathrm{~g}$ for $25 \mathrm{~min}$ at $4^{\circ} \mathrm{C}$ with an Eppendorf centrifuge, and the supernatants were immediately frozen by liquid nitrogen. Protein concentration in the lysates was measured (protein DC assay; BioRad, Richmond, CA) according to the manufacturer's protocol or by AuroDye (Amersham Corp., Arlington Heights, IL) staining of protein blots as described by Li et al. (11).

\section{Immunoprecipitation}

Cell lysates $(130 \mu \mathrm{l})$ containing equivalent amounts of protein were mixed with $25 \mu$ l of antiphosphotyrosine ( $\alpha \mathrm{PY}$ )-agarose beads (Oncogene Science, Inc., Uniondale, NY) for $4 \mathrm{~h}$ at $4^{\circ} \mathrm{C}$. The $\alpha \mathrm{PY}$ beads were centrifuged, washed six times with the solubilization buffer and proteins bound to $\alpha \mathrm{PY}$ were eluted by the treatment with the solubilization buffer containing $1 \mathrm{mM}$ phenylphosphate for $10 \mathrm{~min}$ at $4^{\circ} \mathrm{C}$. The eluted material was mixed with an equal volume of $2 \times$ sample buffer ( $1 \%$ SDS, $0.1 \% \beta$-mercaptoethanol, $0.15 \mathrm{M}$ Tris, $10 \%$ glycerol, $0.02 \%$ bromophenol blue, $1 \mathrm{mM}$ EDTA, pH 6.8), boiled for $5 \mathrm{~min}$, and spun down for $10 \mathrm{~min}$. The samples were then subjected to SDS (12.5\%) PAGE (Phast System; Pharmacia LKB Biotechnology Inc., Piscataway, $\mathrm{NJ}$ ) according to manufacturer's instructions.

\section{Immunoblotting}

The proteins separated on SDS-PAGE were transblotted to nitrocellulose membrane (ProBlot membrane; Applied Biosystems Inc., Foster City, CA ) in 3-[ cyclohexylamide]-1-propanesulfonic acid buffer at 20 $\mathrm{V}, 25 \mathrm{~mA}$ at $15^{\circ} \mathrm{C}$ for $20 \mathrm{~min}$. The membranes were immunostained with the 327 monoclonal antibody to pp60 ${ }^{\mathrm{v}-\mathrm{sr}}$.

\section{Assay for pp $60^{c-s r c}$ protein kinases}

The assays were performed as described (12). In brief, $130 \mu$ l cell lysate prepared as above were incubated with $15 \mu 1327$ monoclonal antibody (Oncogene Science) (13) for $50 \mathrm{~min}$ at $4^{\circ} \mathrm{C}$ and successively with $40 \mu \mathrm{l}$ agarose-bound protein G (Immuno Pure Plus Immobilized Protein G; Pierce, Rockford, IL) for $40 \mathrm{~min}$ at $4^{\circ} \mathrm{C}$. The immunoprecipitates were washed in the solubilization buffer three times and then incubated in $30 \mu \mathrm{l}$ of reaction mixture of $10 \mathrm{mM}$ Tris ( $\mathrm{pH} 7.4), 5 \mathrm{mM} \mathrm{MnCl}, 1 \mu \mathrm{M}$ ATP, $10 \mu \mathrm{Ci}\left[\gamma^{-32} \mathrm{P}\right]$ ATP (New England Nuclear, Boston, MA, 5,000 $\mathrm{Ci} / \mathrm{mmol}$ ) and $1 \mu \mathrm{g}$ enolase (Boehringer-Mannheim Biochemicals, Indianapolis, IN) for $5 \mathrm{~min}$ at $30^{\circ} \mathrm{C}$. The reaction product was mixed with equal volume of $2 \times$ sample buffer, boiled for $5 \mathrm{~min}$, and subjected to SDS-PAGE as described above. The gel was dried and exposed to film (XAR-5; Kodak, Rochester, NY) with intensifying screens (Fischer Biotech, Pittsburgh, PA) for $24 \mathrm{~h}$ at $-70^{\circ} \mathrm{C}$ for autoradiography.

\section{Administration of herbimycin $A$ and RG-13022 to animals} rhIL-1 $\alpha$-injected mice. ICR Swiss white mice (Harlan Sprague-Dawley, Indianapolis, IN) were injected subcutaneously over the right side of the calvariae with $10 \mu \mathrm{g}$ herbimycin A or RG-13022 in $10 \mu \mathrm{l}$ DMSO or DMSO alone four times a day using 27-gauge needles. 30 min later of each injection of herbimycin A or RG-13022, some of the mice received subcutaneous injections of $0.1 \mu \mathrm{g}$ recombinant human IL- $1 \alpha$, kindly supplied by Dr. Lomedico (Hoffman-La Roche, Nutley, NJ) in $10 \mu$ l PBS four times a day over the right side of the calvariae as described previously (14).

Tumor-bearing mice. Nude mice (BALB/c nu/nu; Sprague-Dawley) bearing a well-characterized human squamous cancer $\mathrm{MH}-85$ (15) that manifested hypercalcemia were injected intraperitoneally with $100 \mu \mathrm{g}$ herbimycin A in $0.1 \mathrm{ml}$ DMSO twice a day.

Determination of blood-ionized $\mathrm{Ca}\left(\mathrm{Ca}^{2+}\right)$ and body weight. $\mathrm{Ca}^{2+}$ was determined using a calcium $\mathrm{pH}$ analyzer (model 634; Corning, Medfield, MA) as described (15). Body weight of animals was measured (Lum-O-Gram; Ohaus Scale Corporation, Florham Park, NJ). These measurements were carried out at 9:00 a.m. every other day before the first injection of agents under anesthesia.

Statistical analysis. All data shown are mean \pm SE and were analyzed by ANOVA followed by a paired $t$ test.

\section{Results}

First, we examined the effects of herbimycin A and RG-13022 on the formation of TRAP(+)MNC stimulated with $1,25 \mathrm{D}_{3}$ 
$\left(10^{-8} \mathrm{M}\right)$ in mouse long-term marrow cultures. Herbimycin $\mathrm{A}$ reduced the number of TRAP $(+) \mathrm{MNC}$ in $1,25 \mathrm{D}_{3}$-treated cultures in a dose-dependent manner (Fig. 2). This effect is unlikely to be caused by the cytotoxicity of herbimycin A. Number of stromal cells harvested by trypsinization in control and herbimycin A-treated $(100 \mathrm{ng} / \mathrm{ml})$ marrow cultures at day 6 was not different (control/treated $=3.2 \pm 0.3: 2.9 \pm 0.3 \times 10^{6} /$ well, $n=4$ ) and ${ }^{3} \mathrm{H}$-amino acid incorporation into TCA-insoluble protein in herbimycin A-treated $(100 \mathrm{ng} / \mathrm{ml})$ cultures was not changed (control $/$ treated $=4.2 \pm 0.5: 3.9 \pm 0.2 \times 10^{3}$ $\mathrm{dpm} /$ well, $n=4$ ). In the same cultures, PTH increased apparent activity of pp60 c-src TK, which was measured using enolase as a substrate in bone marrow cell lysates immunoprecipitated with the 327 monoclonal antibody to pp60 ${ }^{\text {c-src }}$. Herbimycin A markedly decreased the activity of $\mathrm{pp} 60^{c-s r c} \mathrm{TK}$, which was increased by PTH (Fig. 3). There were no significant differences in size, shape and nuclear number of TRAP $(+) \mathrm{MNC}$ formed between cultures treated with herbimycin $\mathrm{A}$ and control cultures (data not shown). In contrast, $20 \mu \mathrm{M}(5.36 \mu \mathrm{g} / \mathrm{ml}) \mathrm{RG}-$ 13022, which markedly suppressed epidermal growth factorstimulated TK and growth in several cancer cell lines (16), did not decrease TRAP $(+)$ MNC formation and PTH-stimulated pp60 ${ }^{\text {c-src }}$ TK activity in mouse marrow cultures (Fig. $2 B$ and Fig. 3). Both herbimycin A and RG-13022 did not change
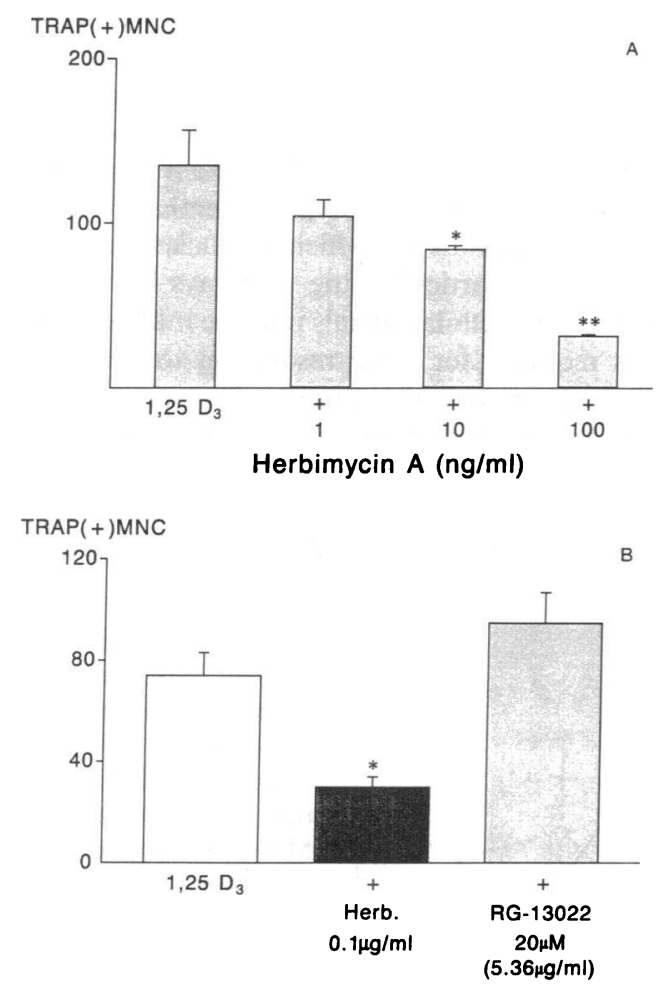

Figure 2. $(A)$ Effect of herbimycin A on TRAP $(+)$ MNC formation in mouse bone marrow cultures. Bone marrow cells $\left(2 \times 10^{6} /\right.$ well, 24-well) were cultured as described in the text in the presence of $10^{-8}$ M $1,25 D_{3}$ with or without increasing concentrations of herbimycin $A$ for $6 \mathrm{~d}$. Data shown are mean \pm SE. *Significantly different from cultures treated with $1,25 \mathrm{D}_{3}$ alone $(P<0.05) .{ }^{* *}$ Significantly different from cultures treated with $1,25 \mathrm{D}_{3}$ alone $(P<0.01)$. $(B)$ Effect of herbimycin A and RG-13022 on TRAP $(+)$ MNC formation in mouse bone marrow cultures. Data shown are mean \pm SE. *Significantly different from cultures treated with $1,25 \mathrm{D}_{3}$ alone $(P<0.01)$.

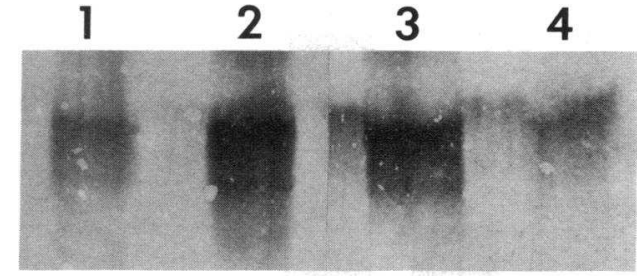

Figure 3. Effect of herbimycin A and RG-13022 on pp60 ${ }^{\text {c-src }}$ TK activity. Bone marrow cells were cultured in the presence of $1,25 \mathrm{D}_{3}$ for $6 \mathrm{~d}$ as described in the text. From day 5 of the culture, cells were incubated with or without $0.1 \mu \mathrm{g} / \mathrm{ml}$ herbimycin A or $20 \mu \mathrm{M}(5.36$ $\mu \mathrm{g} / \mathrm{ml}$ ) RG- 13022 for $24 \mathrm{~h}$ until the end of the culture. At the end of the culture, cells were incubated with or without $50 \mathrm{ng} / \mathrm{ml}$ PTH for $30 \mathrm{~min}$, lysed, and immunoprecipitated with 327 monoclonal antibody. pp $60^{\mathrm{c}-s \mathrm{rc}}$ TK activity was then determined using enolase as a substrate as described in the text. Lane 1, untreated (DMSO); lane 2, PTH (50 ng/ml); lane 3, RG-13022 (20 $\mu \mathrm{M})+$ PTH; and lane 4, herbimycin A $(0.1 \mu \mathrm{g} / \mathrm{ml})+$ PTH. Bands shown are phosphorylated enolase.

pp60 ${ }^{\text {c-src }}$ TK protein levels determined by Western analysis in mouse marrow cultures (data not shown).

Next, we examined the effects of herbimycin A on the capacity of disaggregated rat osteoclasts to form resorption pits on dentine. Herbimycin A decreased the area of pits formed by disaggregated osteoclasts treated with PTH in a dose-dependent manner from 1 to $100 \mathrm{ng} / \mathrm{ml}$ (Fig. 4). Herbimycin A showed no effects on the number of pits formed (Fig. 4). Herbimycin A also inhibited PTH-stimulated bone resorption of fetal rat long bones in organ cultures (Fig. 5). RG-13022 did not show such an effect in the same assay (Fig. 5, data not shown). Bone resorption in untreated cultures was not affected by herbimycin $\mathrm{A}$, and none of the cells (including osteoclasts and stromal cells) in marrow cultures or disaggregated osteoclast assays treated with herbimycin A showed morphologic or numerical changes.

Repeated subcutaneous injection of rhIL-1 $\alpha(0.1 \mu \mathrm{g} /$ mouse, four times a day) induced hypercalcemia in ICR Swiss

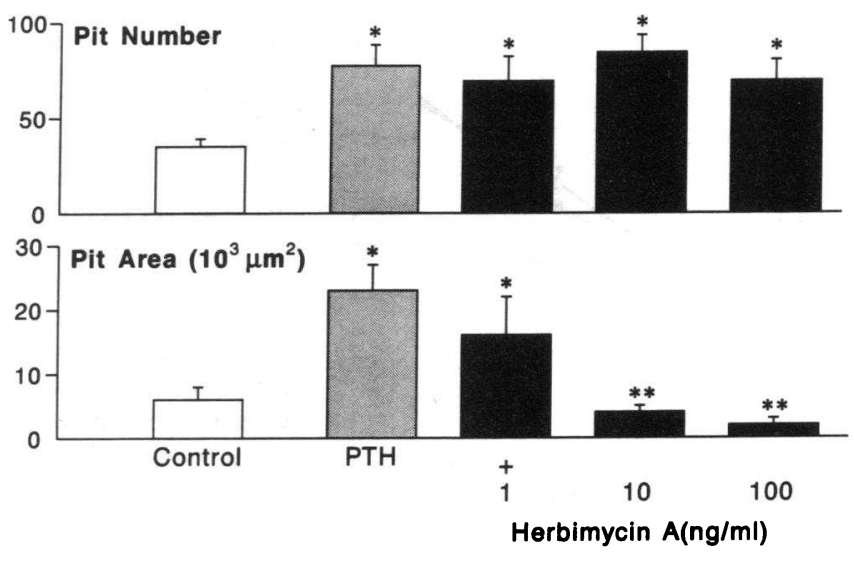

Figure 4. Effect of herbimycin A on resorption pit formation by isolated rat osteoclasts. Isolated osteoclasts were cultured on the dentine slices in the absence or presence of $50 \mathrm{ng} / \mathrm{ml}$ PTH with or without herbimycin A for $24 \mathrm{~h}$. Pit number (top) and pit area (bottom) were then determined as described in Methods. Data shown are mean \pm SE. *Significantly greater than control $(P<0.05) .{ }^{* *}$ Significantly less than cultures treated with PTH alone $(P<0.01)$. 


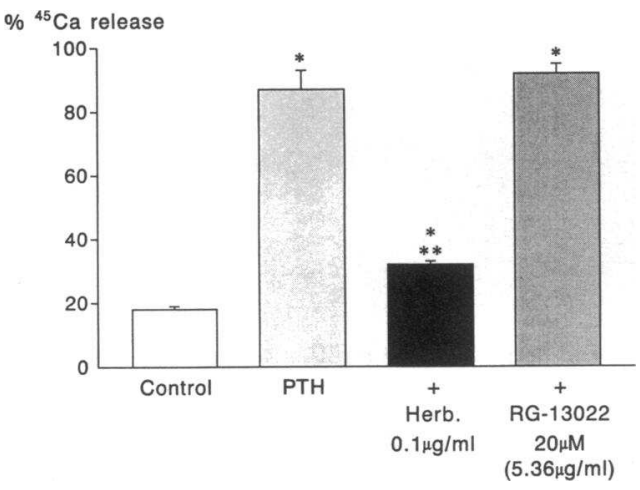

Figure 5. Effect of herbimycin A and RG-13022 on bone resorption in organ cultures of fetal rat long bones. Fetal rat long bones were cultured in the absence or presence of $50 \mathrm{ng} / \mathrm{ml}$ PTH with or without $0.1 \mu \mathrm{g} / \mathrm{ml}$ herbimycin A or $20 \mu \mathrm{M}(5.36 \mu \mathrm{g} / \mathrm{ml})$ RG-13022 for 120 h. Values shown are mean \pm SE. *Significantly higher than control $(P$ $<0.01) .{ }^{* *}$ Significantly less than cultures treated with PTH alone $(P<0.01)$.

mouse (Fig. 6). Previous studies have shown this is caused by increased osteoclastic bone resorption (14). Simultaneous treatment with subcutaneous injections of herbimycin A ( 10 $\mu \mathrm{g} /$ mouse per injection, four injections a day) markedly prevented the development of hypercalcemia induced by rhIL- $1 \alpha$ (Fig. 6).

In preliminary experiments, we found that repeated subcutaneous injections of 400,200 , and $100 \mu \mathrm{g}$ herbimycin A/ mouse per day into untreated ICR Swiss mice killed the animals after 1-3 d. However, administration of herbimycin A at $40 \mu \mathrm{g} /$ mouse per day as shown in Fig. 6 did not show any significant effects on viability, food consumption, body weight, and behavior of animals (data not shown).

RG-13022 (10 $\mu \mathrm{g} /$ mouse per day) administered in the same manner as that of herbimycin $\mathrm{A}$ did not decrease $\mathrm{Ca}^{2+}$ in rhIL- $\alpha$-treated mice (Fig. 6).

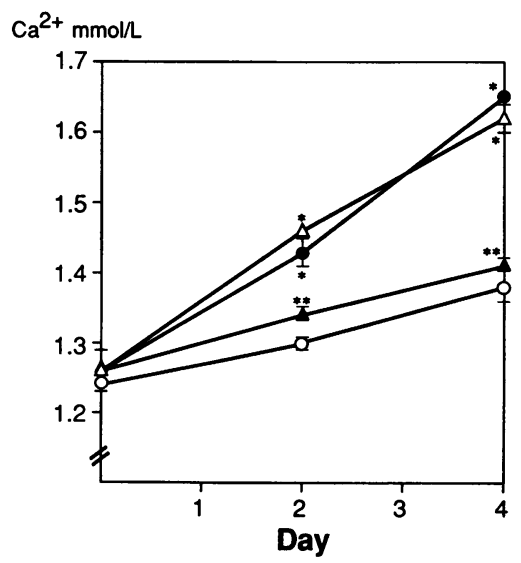

Figure 6. Effect of herbimycin $A$ and RG13022 on rhIL-1 $\alpha$-induced hypercalcemia. ICR Swiss mice (M, 5-6 wk-old; $n=20$ ) were divided into four groups (five mice per group). Open circle, DMSO; closed circle; rhIL-1 $\alpha$ alone $(0.1 \mu \mathrm{g} /$ mouse per injection, four injections a day, subcutaneously on calvariae); closed triangle, rhIL-1 $\alpha$ + herbimycin A ( 10 $\mu \mathrm{g} /$ mouse/injection,

four injections a day subcutaneously on calvariae); open triangle, rhIL-1 $\alpha+$ RG-13022 ( $10 \mu \mathrm{g} /$ mouse per injection, four injections a day subcutaneously on calvariae). $\mathrm{Ca}^{2+}$ was measured at 9:00 a.m. every other day before injection of agents. Normal $\mathrm{Ca}^{2+}$ range: $0.95-$ $1.28 \mathrm{mmol} /$ liter. Values shown are mean \pm SE. *Significantly more hypercalcemic than DMSO-treated mice $(P<0.01)$. **Significantly lower than animals treated with rhIL-1 $\alpha$ alone $(P<0.01)$. $\bigcirc-0$, DMSO; • - $\bullet$ IL-1; $\Delta-\Delta$, herbimycin A + IL-1; $\Delta-\Delta$, RG$13022+$ IL-1.
When herbimycin A ( $200 \mu \mathrm{g} /$ mouse per day) was administered intraperitoneally to hypercalcemic nude mice bearing the human tumor MH-85, which previously was shown to induce hypercalcemia partly by TNF-mediated mechanisms (17), $\mathrm{Ca}^{2+}$ was lowered by day 4 of injection and significantly decreased by day 8 of the administration of the drug (Fig. 7). In contrast, hypercalcemic $\mathrm{MH}-85$ tumor-bearing nude mice that were not treated with herbimycin A showed a progressive increase in $\mathrm{Ca}^{2+}$. Herbimycin A treatment for $8 \mathrm{~d}$ did not show any effect on MH-85 tumor growth (data not shown).

\section{Discussion}

The data reported in this paper show that herbimycin $\mathrm{A}$, which is known to inhibit pp60 ${ }^{\text {c-src }}$ TK activity (2), decreased pp60 6 -src TK activities in mouse bone marrow cells and inhibited the formation of cells with osteoclast characteristics and their bone resorbing capacity in the same culture system. Furthermore, herbimycin A inhibited the capacity of mature osteoclasts to form pits on dentine slices and suppressed bone resorption in organ cultures of fetal rat long bones. More importantly, we found that herbimycin A decreased and prevented rhIL- $1 \alpha$-or tumor-induced hypercalcemia, both of which are associated with increased osteoclastic bone resorption in vivo $(14,15)$. Inhibition of bone resorption by herbimycin A is likely to be, at least in part, associated with suppression of pp60 6 -src $\mathrm{TK}$ activity, since RG-13022, which failed to decrease pp60 $60^{\text {c-src }}$ TK activity, did not inhibit bone resorption. These results are consistent with other observations that suggest that pp60 $60^{\mathrm{c}-s \mathrm{c}} \mathrm{TK}$ is essential and required for normal osteoclast formation, as well as osteoclastic bone resorption, and point to the potential of pharmacologic inhibition of $\mathrm{pp} 60^{\mathrm{c}-s \mathrm{rc}}$ TK in bone resorbing cells as a therapeutic approach to inhibition of increased bone resorption and hypercalcemia.

The molecular mechanisms by which osteoclasts resorb bone are still unclear. In particular, the pathways by which osteoclasts transduce extracellular signals into the intracellular machinery that is required for bone resorption to occur is poorly understood. However, the recent observation that pp60 6 -src TK-deficient mice manifest osteopetrosis in which osteoclast function is impaired has raised the possibility that pp60 ${ }^{\text {c-src }}$ TK might mediate signal transduction in osteoclasts (1). Consistent with this notion, our data have shown that

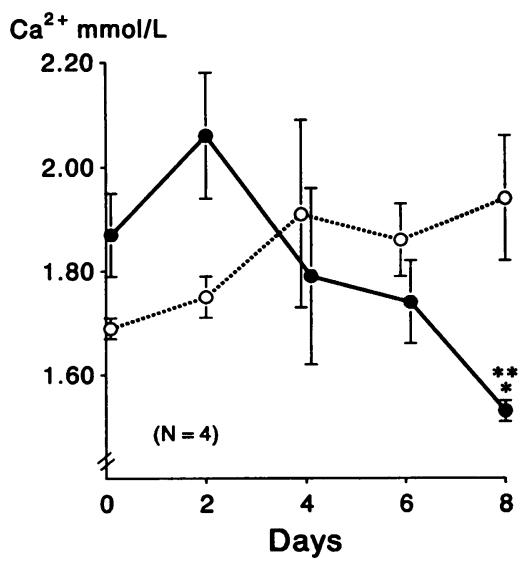

Figure 7. Effect of herbimycin A on tumor-induced hypercalcemia. Nude mice $(n=8)$ were inoculated with a human squamous cancer MH-85 subcutaneously. 6 wk later, when animals manifested hypercalcemia, herbimycin A (closed circles) 100 $\times \mu \mathrm{g} /$ mouse per injection, two injections per day or DMSO (open circles) was given to these mice intraperitoneally every day for 8

d. Data shown are mean \pm SE. *Significantly lower than DMSOtreated group $(P<0.05) .{ }^{* *}$ Significantly lower than animals before herbimycin A treatment $(P<0.05) .-0-$, DMSO; $-\bullet-$, herbimycin $A(200 \mu \mathrm{g} /$ mouse per day $)$. 
PTH, a potent stimulator of osteoclastic bone resorption, increased pp60-src $\mathrm{TK}$ levels in marrow cell cultures in which there were considerable numbers of osteoclasts. In addition, we have recently found that calcitonin inhibits pp60-src $\mathrm{TK}$ activity in marrow cell cultures and decreases resorption pit formation by TRAP $(+)$ MNC (manuscript submitted for publication). Furthermore, we have also found recently that osteoclasts in pp60 ${ }^{\text {c-src }}$ TK-deficient mice are not able to form ruffled borders and resorption pits in response to PTH and IL-1 (18). Taken together, these findings indicate that pp60 ${ }^{\mathrm{c}-s r c}$ TK mediates osteoclastic bone resorption and makes it feasible to use pp60 ${ }^{\text {c-src }}$ TK inhibitors as potent inhibitors of bone resorption.

None of the currently available inhibitors of bone resorption are entirely satisfactory. Estrogens have only been used effectively in postmenopausal females and the mode of action of estrogen remains unclear. Bisphosphonates are effective, but are absorbed poorly when used orally. Again, their mode of action to inhibit bone resorption remains uncertain. In the case of herbimycin A, its inhibitory effects on bone resorption are most likely due to its capacity to inhibit pp60 $60^{\text {-src }} \mathrm{TKs}$, and this or related TK inhibitors that can be used orally may be useful therapies in common diseases of increased osteoclast activity such as postmenopausal osteoporosis, hypercalcemia of malignancy, and Paget's disease.

Although herbimycin A has been shown to inhibit pp60 $60^{\text {csrc }}$ TK and have no effects on protein kinase $A$ and protein kinase C (2), its absolute specificity for pp60 c-src TK is unknown. Since pp $60^{\mathrm{c}-s r c} \mathrm{TK}$ is increased in active osteoclasts during bone resorption, it seems likely that the effects of herbimycin $\mathrm{A}$ to inhibit bone resorption are related to its capacity to inhibit pp60 ${ }^{\text {c-src }}$ TK.

Toxicity was not likely to account for the effects we observed. Since herbimycin $A$ is an irreversible inhibitor of pp60 $6{ }^{\text {-src }}$, we were not able to exclude toxicity by showing that transient exposure to herbimycin A would not impair bone resorption stimulated by PTH. However, herbimycin A did not affect the numbers of stromal cells and pits formed by osteoclasts, decrease protein synthesis by marrow cells, cause detachment of osteoclasts or stromal cells from either plastic culture dishes or dentine, or reduce control resorption in the organ culture assays. Herbimycin A-treated animals did not manifest any marked changes in food consumption, body weight, and motional activity.

In conclusion, our data suggest that herbimycin A may have therapeutic potential as a bone resorption inhibitor in disease states where bone resorption is enhanced.

\section{Acknowledgments}

We are grateful to Dr. Asher Zilberstein for the generous gift of RG13022, and Thelma Barrios and Nancy Garrett for their secretarial assistance. This work was supported by grants AR28149, AR39529, and DE08569 from the National Institutes of Health.

\section{References}

1. Soriano, P., C. Montgomery, R. Geske, and A. Bradley. 1991. Targeted disruption of the c-src proto-oncogene leads to osteopetrosis in mice. Cell. 64:693-702.

2. Uehara, Y., and H. Fukazawa. 1991. Use and selectivity of herbimycin A as inhibitor of protein-tyrosine kinase. Methods Enzymol. 201:370-379.

3. Yaish, P., A. Garzit, C. Gilon, and A. Levitzki. 1988. Blocking of EGF-dependent cell proliferation by EGF receptor kinase inhibitors. Science (Wash DC). 242:933-935.

4. Lyall, R. M., A. Zilberstein, A. Gazit, C. Gilon, A. Levitzki, and J. Schlessinger. 1989. Tyrphostins inhibit epidermal growth factor (EGF)-receptor tyrosine kinase activity in living cells and EGF-stimulated cell proliferation. J. Biol. Chem., 264:14503-14509.

5. Raisz, L. G. 1965. Bone resorption in tissue culture. Factors influencing the response to parathyroid hormone. J. Clin. Invest. 44:103-116.

6. Takahashi, N., H. Yamana, S. Yoshiki, G. D. Roodman, G. R. Mundy, S. J. Jones, A. Boyde, and T. Suda. 1988. Osteoclast-like cell formation and its regulation by osteotropic hormones in mouse bone marrow cultures. Endocrinology. 122:1373-1382.

7. Oreffo, R. O. C., G. R. Mundy, S. Seyedin, and L. Bonewald. 1989. Activation of the bone derived latent TGF beta complex by isolated osteoclasts. Biochem. Biophys. Res. Commun. 158:817-823.

8. Oreffo, R. O. C., L. F. Bonewald, A. Kukita, I. R. Garrett, S. M. Seyedin, D. Rosen, and G. R. Mundy. 1990. Inhibitory effects of the bone-derived growth factors osteoinductive factor and transforming growth factor- $\beta$ on isolated osteoclasts. Endocrinology. 126:3069-3075.

9. Boyde, A., N. N. Ali, and S. I. Jones. 1984. Resorption of dentine by isolated osteoclasts in vitro. Br. Dent. J. 156:216-220.

10. Li, W., and J. Schlessinger. 1991. Platelet-derived growth factor (PDGF)induced disulfide-linked dimerization of PDGF receptor in living cells. $\mathrm{Mol}$. Cell. Biol. 11:3756-3761.

11. Li, K. W., W. P. Geraerts, R. van Elk, and N. Josse. 1989. Quantification of proteins in the subnanogram and nanogram range: comparison of the AuroDye, FerriDye, and India Ink staining methods. Anal. Biochem. 182:44-47.

12. Thomas, J. E., P. Soriano, and J. S. Brugge. 1991. Phosphorylation of c-src on tyrosine 527 by another protein tyrosine kinase. Science (Wash. DC). 254:568-571.

13. Lipsich, L. A., A. J. Lewis, and J. S. Brugge. 1983. Isolation of monoclonal antibodies that recognize the transforming proteins of avian sarcoma viruses. $J$. Virol. 48:352-360.

14. Boyce, B. F., T. B. Aufdemorte, I. R. Garrett, A. J. P. Yates, and G. R. Mundy. 1989. Effects of interleukin-1 on bone turnover in normal mice. Endocrinology. 125:1142-1150.

15. Yoneda, T., T. B. Aufdemorte, R. Nishimura, N. Nishikawa, M. Sakuda, M. M. Alsina, J. B. Chavez, and G. R. Mundy. 1991. Occurrence of hypercalcemia and leukocytosis with cachexia in a human squamous cell carcinoma of the maxilla in athymic nude mice. A novel experimental model of 3 concomitant paraneoplastic syndromes. J. Clin. Oncol. 9:468-477.

16. Yoneda, T., R. M. Lyall, M. M. Alsina, P. E. Parsons, A. P. Spada, A Levitzki, A. Zilberstein, and G. R. Mundy. 1991. The antiproliferative effects of tyrosine kinase inhibitors tyrphostins on a human squamous cell carcinoma in vitro and in nude mice. Cancer Res. 51:4430-4435.

17. Yoneda, T., M. M. Alsina, J. B. Chavez, L. Bonewald, R. Nishimura, and G. R. Mundy. 1991. Evidence that tumor necrosis factor plays a pathogenetic role in the paraneoplastic syndromes of cachexia, hypercalcemia, and leukocytosis in a human tumor in nude mice. J. Clin. Invest. 87:977-985.

18. Boyce, B. F., T. Yoneda, P. Soriano, and G. R. Mundy. 1992. Requirement of pp60 $0^{\mathrm{c}-\mathrm{arc}}$ expression for osteoclasts to form ruffled borders and resorb bone. J. Clin. Invest. 90:1622-1627. 